\section{CITAÇÃO}

Manhiça, A. M., Nhalevilo, E. A., Antunes,

S. C. (2020)

Reserva Especial de Maputo,

Rev. Ciência Elem., V8(03):045.

doi.org/10.24927/rce2020.045

\section{EDITOR}

José Ferreira Gomes,

Universidade do Porto

\section{EDITOR CONVIDADO}

José Francisco Rodrigues

Universidade de Lisboa

\section{RECEBIDO EM}

24 de janeiro de 2020

\section{ACEITE EM}

21 de julho de 2020

\section{PUBLICADO EM}

30 de setembro de 2020

\section{COPYRIGHT}

(C) Casa das Ciências 2020.

Este artigo é de acesso livre, distribuído sob licença Creative Commons com a designação CC-BY-NC-SA 4.0, que permite a utilização e a partilha para fins não comerciais, desde que citado o autor e a fonte original do artigo.

rce.casadasciencias.org

\title{
Reserva Especial de Maputo
}

\section{Uma visão histórica e a sua importância na Conservação da Biodiversidade}

\author{
André Machava Manhiça*, Emília Afonso Nhalevilo ${ }^{\ddagger}$, Sara C. Antunes ${ }^{\ddagger}$ \\ * Universidade Pedagógica de Maputo \\ ${ }^{1}$ Universidade Púnguè \\ ${ }^{\ddagger}$ CIIMAR/ Universidade do Porto
}

O estudo na Reserva Especial de Maputo, em Moçambique, tem por objetivo principal o conhecimento das comunidades locais no seu contributo para um modelo mais sustentável de conservação e gestão da biodiversidade. 0 etnoconhecimento centrado e ainda presente nas comunidades locais tem um valor incalculável para a conservação e gestão sustentável da biodiversidade em Moçambique. Por outro lado, é preciso conhecer, compreender e garantir a continuidade das práticas tradicionais utilizadas pelas comunidades locais, para que este conhecimento seja mantido e aplicado numa perspetiva de gestão adaptativa sustentável.

\section{A Reserva Especial de Maputo}

Moçambique possui um conjunto de áreas de conservação distribuídas por todo o território com diversos sistemas ecológicos, ricos em espécies endémicas ${ }^{1}$. A Reserva Especial de Maputo (REM), anteriormente denominada de Reserva de Elefantes de Maputo, é uma das mais importantes áreas de conservação em Moçambique. Esta reserva apresenta características que a tornam singular, pois inclui ecossistemas marinhos e terrestres, constituindo um património natural do País e, particularmente, do Distrito de Matutuíne ${ }^{1}$.

A REM (FIGURA 1) fica no Distrito de Matutuíne na Província de Maputo no Sul de Moçambique, a Sul da Península de Machangulo². 0 Distrito de Matutuíne ocupa uma área de cerca de $5340 \mathrm{~km}^{2}$ e possui uma população com 37239 habitantes ${ }^{3}$. Esta área é caracterizada por elevados índices de biodiversidade e endemismos em termos florísticos, tendo sido incluída no centro de endemismo de Maputaland-Pondoland (FIGURA 1A)). As fronteiras atuais da REM são a Baía de Maputo a Norte; o Oceano Índico a Este; o Rio Maputo, Rio Futi e uma linha de $2 \mathrm{~km}$ a Este da estrada de Salamanga - Ponta do Ouro a Oeste, e a Sul pela extremidade Sul do Lago Xingute e do Lago Piti ${ }^{8}$ (FIGURA 1B)). 0 centro de Maputaland Pondoland com $26734 \mathrm{~km}^{2}$ caracteriza-se pela variedade de lagos, tais como os Lagos Piti, Xingute e Satine no lado moçambicano e outros tantos no lado Sul africano. 

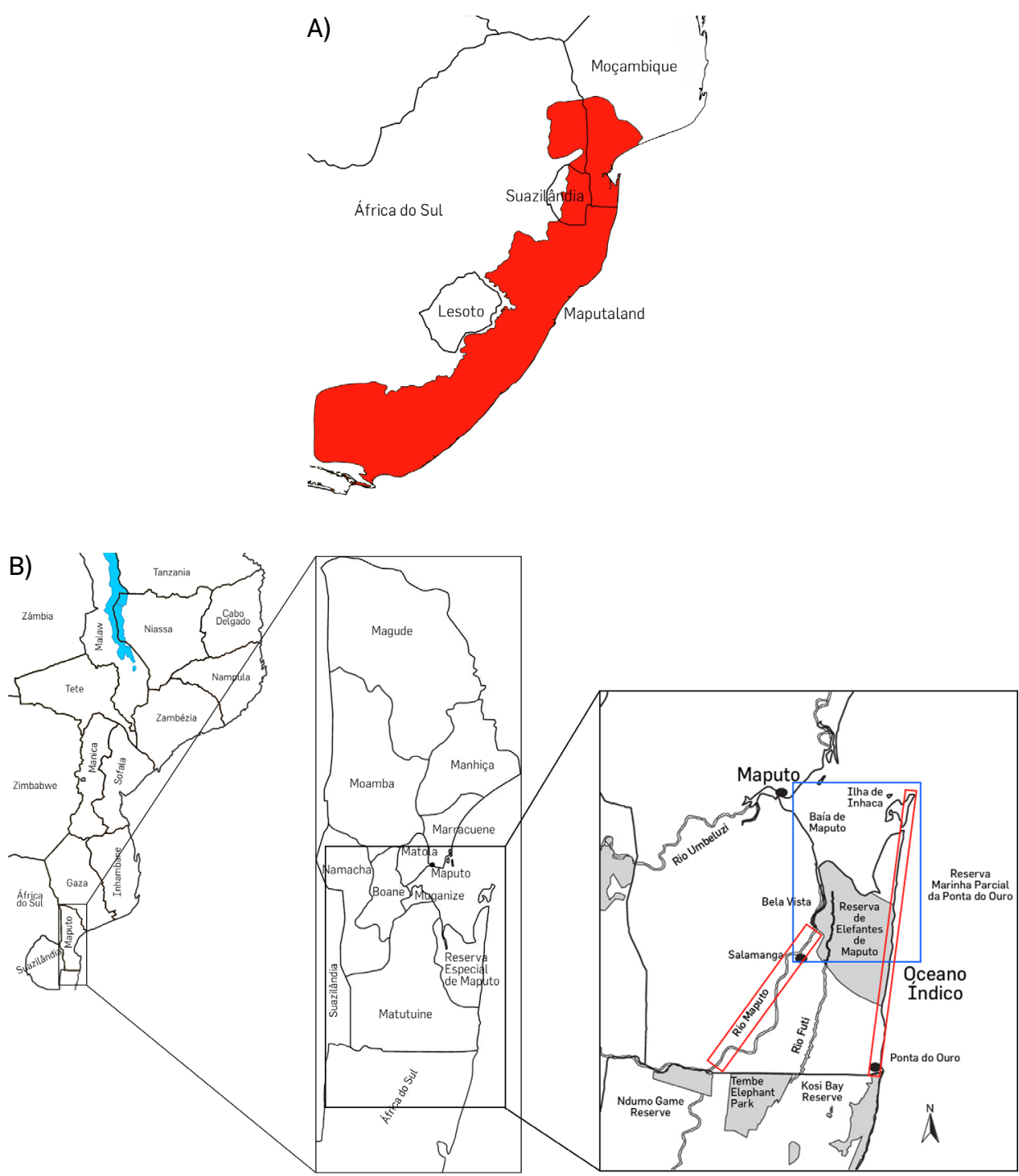

FIGURA 1. A) Localização da região de Maputaland. B) Localização da Reserva Especial de Maputo - REM (adaptado de Ntumi et al., 2005 South African Journal of Wildlife Research 35(2): 139-146). A azul está representada a Península de Machangulo e a vermelho o Rio Maputo e a Reserva Marinha Parcial da Ponta de Ouro.

A REM é composta por duas áreas principais, a Área Central Terrestre, incluindo o Corredor do Futi, e a Área Marinha Protegida (Reserva Marinha Parcial de Ponta do Ouro) (FIGURA 1B) - evidenciado a vermelho). O Corredor do Futi liga a área central da REM em Moçambique com o Parque de Elefantes de Tembe na África do Sul e serve como corredor ecológico destinado à gestão da vida selvagem e também à gestão de habitats (FIGURA 1B)). A Reserva Marinha Parcial de Ponta do Ouro pretende preservar e proteger as espécies costeiras e marinhas e os seus habitats, com uma área de $678 \mathrm{~km}^{2}$, onde se incluem as dunas primárias da praia de Ponta do Ouro até à Ilha de Inhaca².

A REM foi formalmente estabelecida em 1932 pela administração colonial como uma coutada usada principalmente para recreação e para captura de troféus de caça. Um ano mais tarde foi elevada ao estatuto de Reserva. No entanto, a terra proclamada como Reserva foi alienada do povo Tsonga, grupo étnico mais abundante na Província de Maputo². Ao longo dos tempos, a Reserva foi sujeita a várias alterações dos seus limites devido a conflitos com as comunidades locais e à competição pelo uso da terra ${ }^{5}$. 0 diploma legis- 
lativo no 1994 de 1960 cria a Reserva de Elefantes de Maputo ${ }^{6}$, com o objetivo principal de conservação dos elefantes - Loxodonta africana (Blumenbach, 1797), espécie chave desta área natural ${ }^{2}$. Porém, após a introdução de outras espécies e a perceção do valor da biodiversidade da REM, esta foi designada como a Reserva Especial de Maputo em 1969,

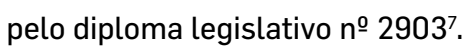

A REM é parte integrante da área de conservação transfronteiriça dos Libombos (cordilheira montanhosa vulcânica que separa Moçambique da Suazilândia), onde se encontra uma vasta gama de habitats e um notável valor de biodiversidade. Por este reconhecimento, esta área está ligada ao Maputaland Centre of Global Plant Diversity, área descrita com elevada riqueza e diversidade de espécies e endemismos. 0 Maputaland Centre of Global Plant Diversity faz parte do centro de endemismo de plantas, um dos quatro identificados na África Austral. Por outro lado, esta Reserva encontra-se na posição estratégica do limite sul dos trópicos e por isso contém diversas espécies características de zonas temperadas do sul. Mais ainda, apresenta uma surpreendente variedade e combinação de ecossistemas e comunidades de plantas, algumas das quais sem qualquer estatuto de proteção na restante África Austral ${ }^{8}$. A riqueza específica está reconhecida através da ocorrência de cerca de 1100 espécies de plantas vasculares, no entanto, reconhece-se que este número pode estar subestimado e atingir 2000 a 3000 espécies $^{9}$. Destas, pelo menos 186 espécies e 4 géneros, nomeadamente Brachychloa, Ephippiocarpa, Helichrysopsis e Inhambanella são endémicos deste centro, sendo que a maioria destas espécies são raras e pouco conhecidas $^{9}$. Este centro contém ainda cerca de 2500 espécies de animais das quais 225 espécies e três géneros são endémicos. Da diversidade de fauna que aqui se pode encontrar destacam-se ainda várias espécies endémicas nos grupos de vertebrados (Chelonia mydas - tartaruga-verde, Nectarinia neergaardi, passeriforme ameaçado por perda de habitat) e alguns invertebrados (Gullela daedalea e G. triglochis - gastrópodes terrestres) ${ }^{10}$.

o Centro de Maputaland - Pondoland é único, quando comparado com outros centros, visto que o elevado número de espécies endémicas se encontra disperso sobre quase todo o espectro taxonómico. Numa perspetiva de conservação da REM, com a sua potencial ligação ecológica ao Parque de Elefantes de Tembe na África do Sul, é essencial identificar alvos específicos de conservação dentro de Maputaland (através da manutenção da biodiversidade existente) $)^{2}$.

Desde a sua criação, a REM sofreu mudanças significativas na sua biodiversidade, como consequência das atividades antrópicas. Os conflitos entre as comunidades locais e a existência da Reserva na terra dos seus ancestrais continuaram mesmo depois da independência de Moçambique em $1975^{5}$. Este contexto levou a que o governo local decidisse, em 1980 , retirar as pessoas que viviam no interior da Reserva para a área envolvente. Mavuku$z a$, líder desse povo, não concordando com a ação do governo, regressou e reassentou-se no interior da Reserva ${ }^{5}$. De facto, várias comunidades residentes no seu interior e na zona tampão, dependem dos recursos naturais da REM para a sua subsistência. Nesta interação com a natureza, as comunidades locais construíram um corpo de etnoconhecimento e práticas com valor na conservação e sustentabilidade da biodiversidade, que é necessário conhecer e preservar. No entanto, o conflito homem - animal, devido à presença de elefantes, tem levado os gestores da REM a incentivarem as comunidades a abandonar o seu interior para as áreas circundantes. No entanto, estas ações poderão acarretar o risco da perda do etnoconhecimento e das práticas desenvolvidas por estas comunidades. 
Conceição e seus colaboradores ${ }^{11}$ estudaram o impacto das políticas de conservação da natureza na dinâmica das comunidades locais no Parque Nacional do Limpopo (Moçambique) e consideraram que o modelo adotado para gestão do parque, que consiste no reassentamento da população fora do parque, não era o mais adequado. Este modelo provocou perturbações no seio das comunidades locais e trouxe profundas mudanças sociais e ecológicas. Essas mudanças sociais estimularam conflitos de identidade cultural, de posse de terra, sentimento de perda e revolta, resultando numa sobre-exploração dos recursos faunísticos, através da caça furtiva ${ }^{11}$. Na mesma perspetiva, Arruda ${ }^{12}$, num estudo sobre populações tradicionais brasileiras e a proteção dos recursos naturais em unidades de conservação, afirma que as populações tradicionais ao serem retiradas das suas áreas de origem são impedidas de reproduzir o seu modo de vida e acabam por desenvolver uma postura anticonservacionista, passando a desenvolver práticas predatórias do meio ambiente como único meio de garantir sua subsistência ${ }^{12}$. As pessoas retiradas e realojadas passam a encarar os recursos naturais da área como perdidos para a comunidade. Em função disso, as comunidades afetadas pouco fazem em prol do manejo da área de conservação, desenvolvendo muitas vezes práticas clandestinas de superexploração no interior da própria área a preservar. Botkin citado em Arruda ${ }^{12}$ estudou o impacto da retirada das populações no Tsavo National Park na África do Leste. Este modelo que foi adotado para proteger e controlar a população de elefantes provocou a deterioração da terra no interior dos limites da área. No entanto, a área envolvente habitada pelas comunidades humanas expulsas permaneceu florestado e preservado. Este modelo de ação tem também ocorrido na REM, onde as comunidades residentes no seu interior têm vindo a ser retiradas e relocadas numa zona tampão (e.g., comunidades de Gwengo e Madjadjane). No entanto, o líder da comunidade de Gwengo considera que a REM se apoderou do espaço que pertencia aos seus antepassados, não reconhecendo a medida como uma mais valia para a REM. Mais ainda, esta medida não foi bem vista pelas comunidades locais uma vez que a REM impôs limitações no uso dos recursos naturais, sem criar alternativas de sobrevivência para as comunidades.

Até ao início de 1980 a integridade da Reserva foi gravemente afetada pelas povoações humanas, através da criação de gado e de várias outras atividades, que ocorriam dentro dos limites da REM. A Guerra Civil subsequente teve também impactos na Reserva, resultando numa redução nas populações de mamíferos de grande porte (e.g., o elefante- Loxodonta africana, Matagaiça - Hippotragus equinus). Por outro lado, foi nesta altura que se procedeu à relocação da maioria das comunidades residentes na REM em áreas rurais circundantes. No entanto, com o fim da guerra civil, as pessoas tenderam a voltar para o interior da Reserva e a ocuparem as áreas envolventes à procura dos recursos naturais disponíveis ${ }^{2}$. Atualmente, há cerca de 600 pessoas, pertencentes a quatro comunidades, a viverem dentro da área ou na zona de proteção total da REM. Vodouhê e colaboradores ${ }^{13}$ avaliaram a perceção comunitária da conservação da biodiversidade dentro de áreas protegidas no Benin (Região ocidental de África). Este estudo permitiu perceber as perceções das comunidades locais e usá-las como ponto de partida para melhorar a relação parque-pessoas, e que esta relação poderia ajudar as equipas de gestão a envolver de forma mais eficaz as comunidades locais e assim melhorar a sua consciencialização sobre a conservação da biodiversidade dentro do parque ${ }^{13}$. No caso da REM, embora exista uma ligação entre a Reserva e as comunidades, não existem ainda estudos que documentem o conhe- 
cimento que as comunidades locais possuem e que contributo poderiam dar na construção de um modelo de gestão que garanta, simultaneamente, a conservação da biodiversidade, do etnoconhecimento e o desenvolvimento das comunidades.

Numa perspetiva de sustentabilidade dos recursos naturais, a REM em parceria com outras instituições desenvolve atualmente projetos que visam apoiar os que desejam abandonar o interior da reserva para se instalar fora desta, argumentando que ocorrem muitas mortes resultantes de ataques de elefantes. Nesse sentido, foi estabelecido o Fundo de Desenvolvimento Comunitário para apoiar as comunidades na implementação de diversos projetos de valorização da REM (e.g., estabelecimento de um Lodge Comunitário - local de hospedagem). A FIGURA 2 apresenta outros exemplos do desenvolvimento desses projetos, à esquerda a produção de mel e à direita o cultivo e apanha de piri-piri'14. No entanto, pode-se questionar até que ponto o conhecimento e práticas tradicionais das comunidades envolvidas têm sido explorados para o desenvolvimento desses projetos, por exemplo, na produção de mel. A REM tem também desenvolvido projetos com as comunidades situadas na zona tampão, que de alguma forma dependem da reserva, com o objetivo de aliviar a pressão que estas comunidades fazem sobre os recursos naturais da REM.
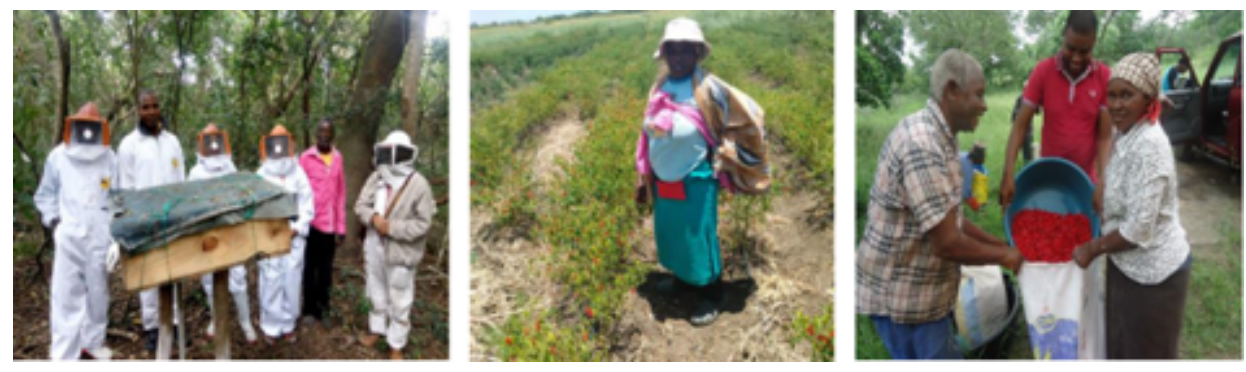

FIGURA 2. Projetos em curso na REM. A figura da esquerda está relacionada com a produção de mel (Fonte: porqueanima.com/rem/) e as outras duas com o cultivo e comercialização de piri-piri.

Neste contexto, a REM tem fornecido sementes (sementes de hortícolas, no projeto de agricultura de conservação) às comunidades instaladas na zona tampão para que estas desenvolvam a sua agricultura de subsistência sem ter de recorrer aos recursos naturais da REM (FIGURA 3). Adicionalmente, e de modo a proteger também os ecossistemas aquáticos, a REM tem estado a abrir furos de água junto às comunidades (FIGURA 3) para que estas não necessitem de entrar na REM à procura de água (e.g., recorrendo ao rio Futi). Vodouhê e colaboradores ${ }^{13}$ afirmam que uma perceção positiva das comunidades sobre a gestão dos parques é uma boa oportunidade para a conservação da diversidade biológica. Deste modo, as comunidades locais tornam-se mais recetivas e ativas na conservação da biodiversidade, nomeadamente se percebem que podem beneficiar das atividades de conservação ${ }^{13}$. Relativamente à REM, no seu interior não existem projetos sociais, desencorajando assim a permanência das comunidades dentro da Reserva, e evitando a entrada de outras pessoas nesta área protegida. No entanto, este cenário pode criar uma perceção negativa das comunidades não favorecendo a conservação da biodiversidade na REM.

Arruda $^{12}$ afirma que no processo de reassentamento, quando as populações resistem e permanecem, as necessidades de exploração dos recursos naturais inerentes ao seu modo de vida e sobrevivência raramente são reconhecidas, sendo obrigadas a superexplorar as áreas ainda acessíveis ${ }^{12}$. A falta de projetos sociais para as comunidades ainda no interior 
da REM parece atestar o argumento de Arruda, tal como ocorre com as comunidades de Mavukuza e Tsolombane. Estas comunidades estão privadas dos benefícios dos projetos sociais decorrentes da conservação da biodiversidade, porém continuam dependentes dos recursos da REM, cuja exploração está limitada.
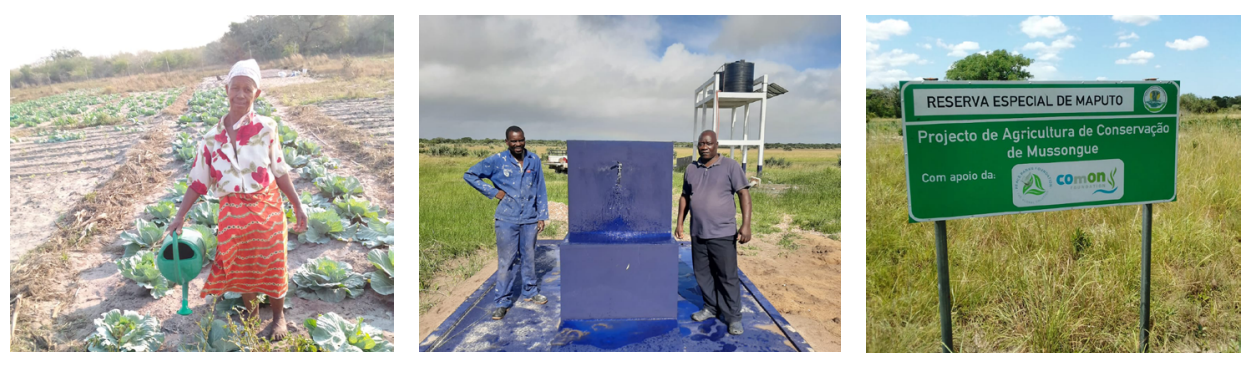

FIGURA 3. Projetos de rega e de abertura de furos de água e Agricultura de Conservação na REM.

Por outro lado, as comunidades locais, em situações específicas, precisam de utilizar os recursos naturais da REM. Por exemplo, as comunidades locais utilizam e dependem de plantas medicinais para o tratamento de doenças, uma vez que não existe um posto de saúde nas proximidades. Mais ainda, a comunidade de Matchia (uma das comunidades que vive na zona tampão) vive da venda de plantas medicinais que recolhe na REM. Porém as plantas medicinais que existem no interior da REM também ocorrem na zona tampão e em outras zonas de Maputaland, pelo que as medidas de proteção implementadas no interior da REM deveriam ser estendidas à zona tampão. No entanto, e de modo a demonstrar o valor das plantas medicinais que ocorrem na REM e assim valorizar a sua riqueza específica são necessários mais estudos científicos, etnobotânicos e etnoecológicos para caraterizar as suas propriedades (e.g., curativas).

A gestão da REM tem também demonstrado interesse em ações de divulgação de educação ambiental com as comunidades locais, ações essas que têm sido desenvolvidas pelo departamento comunitário da REM. Durante este processo, o conhecimento local sobre as diversas práticas naturais tem sido a base da atuação, recorrendo-se para o efeito a diversas atividades lúdicas como peças teatrais e a ações de sensibilização e de participação das comunidades nas ações de gestão e monitorização da REM. Estudando as perceções dos residentes comunitários do Parque Nacional de Masoala em Madagascar, Ormsby e Kaplin ${ }^{15}$ concluíram que programas de educação ambiental e comunicação direta com a comunidade (providenciados pelos funcionários do Parque) podem ser uma forma de evitar ações nefastas sobre os recursos naturais e melhorar a relação entre os moradores locais e os funcionários do parque ${ }^{15}$. Um outro exemplo da relação entre os gestores das áreas protegidas e as comunidades locais é o do Parque Nacional Pendjari, em Benin ${ }^{13}$. Neste, o envolvimento da comunidade local na gestão do Parque, por meio de Associações de Vilas para o Manejo das Reservas de Vida Selvagem, reforçou as perceções positivas sobre a conservação da biodiversidade. Criou-se assim uma parceria entre as associações e a equipa do parque ${ }^{13}$. Países como Brasil, China, Índia, Tanzânia, Quénia e Angola são alguns exemplos de sucesso na conservação da biodiversidade de reservas naturais após a incorporação maciça das comunidades locais e das suas práticas culturais nas estratégias nacionais e nos planos de ação para a conservação da biodiversidade ${ }^{16}$. Relativamente à REM, este é um aspeto que se pretende avaliar em vários estudos em curso, integrando as 
comunidades no modelo de gestão da REM e avaliar de que modo o seu etnoconhecimento pode ser usado como ferramenta de conservação da biodiversidade, constitui um dos objetivos do estudo proposto.

O envolvimento das comunidades em projetos de conservação tem sido defendido por vários autores. Hunt e colaboradores ${ }^{17}$ referem que as abordagens dominantes para a conservação e desenvolvimento se baseiam na perceção histórica das regiões rurais como fontes de recursos naturais, mão-de-obra ou serviços ambientais ${ }^{17}$. Os resultados dessas abordagens muitas vezes resultaram em ambientes diminuídos e populações desprivilegiadas havendo, por isso, propostas de abordagens alternativas, enraizadas em distintas identidades culturais das comunidades e reivindicações para maior controle sobre a terra e desenvolvimento. Contudo, para que a conservação alcance um envolvimento comunitário mais eficaz, são necessárias abordagens adaptativas de cogestão de longo prazo que definam claramente a participação local, a capacidade de construção de todos os stakeholders e os níveis de participação e de monitorização em todas as etapas da gestão ${ }^{18}$. A cultura organizacional das agências de conservação deve começar por perceber a população local como sendo potenciais parceiros e não como caçadores furtivos perpétuos ${ }^{19}$. De acordo com informação recolhida sobre a REM, as comunidades que aí ocorrem possuem um corpo de conhecimento e práticas tradicionais com potencial para a conservação da biodiversidade. Este reconhecimento evidencia que estas comunidades podem ser valiosos parceiros para o desenvolvimento de um modelo de conservação mais sustentável.

\section{Ameaças à Biodiversidade da Reserva Especial do Maputo}

Atualmente a biodiversidade da REM (FIGURA 4) encontra-se ameaçada devido a vários fatores, tendo sido identificados como os de maior pressão a existência de comunidades a viver dentro da reserva, a caça ilegal, o fogo descontrolado, os conflitos entre as comunidades locais e os elefantes, e a reduzida capacidade de gestão que ocorre na área².
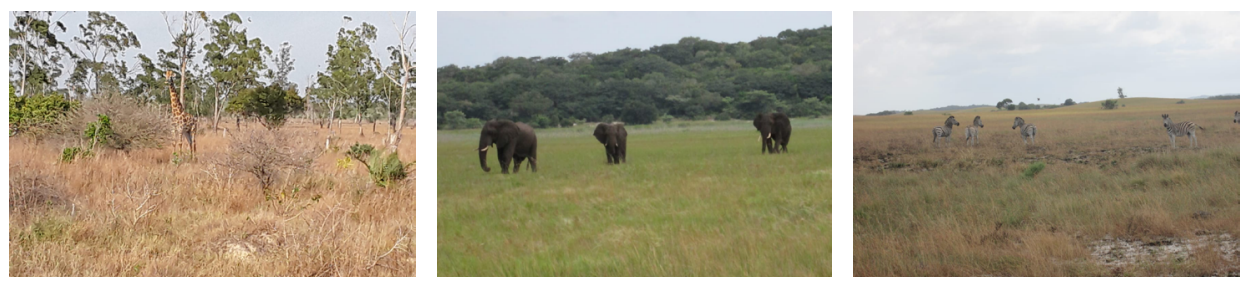

FIGURA 4. Aspetos gerais da diversidade de mamíferos que se pode observar na REM (e.g., girafas, elefantes, zebras).

Para além destas ameaças, o corte insustentável de plantas medicinais constitui também uma ameaça significativa para as diferentes espécies de plantas. Apesar desta ameaça, as políticas atuais de gestão da REM não obrigam à apreensão das plantas recolhidas por indivíduos que passem na Reserva. No entanto, procura recolher informação sobre o número de plantas colhidas, o local de recolha e a sua distribuição e identificação pelos respetivos nomes vernaculares. Adom ${ }^{16}$ considera que os gestores de estratégias, de programas e iniciativas de conservação da biodiversidade, devem aprender com a incorporação da população local e das suas práticas culturais. Ao aprender sobre as práticas de gestão que as comunidades locais empregam no terreno e os seus efeitos ecológicos, os gestores florestais podem expandir os seus conhecimentos e encontrar novas formas 
de alcançar objetivos específicos de gestão e de conservação de forma mais direcionada e com a possibilidade de resultados mais eficazes ${ }^{20}$. É baseado nesta perspetiva que se orienta uma proposta de estudo para a REM, com vista a avaliar a possibilidade do contributo das comunidades locais no desenvolvimento de um modelo de gestão e de conservação da biodiversidade que as integre nas ações e decisões.

Uma ameaça atual que tem fragilizado a integridade da região e nomeadamente a REM tem sido o aparecimento de espécies invasoras ${ }^{2}$ como Acacia cyclops e A. mearnsii, Lantana camara, Psidium guajava, Rubus spp. e Solanum mauritianum). Destaca-se ainda o eucalipto, pois o processo de remoção e controlo tem sido bastante complicado e dispendioso. Mais ainda, os períodos de seca severa que se têm verificado no Rio Futi e nas lagoas adjacentes é outra realidade que ameaça diversas espécies, nomeadamente aquáticas. 0 Rio Futi caracteriza-se por extensões de canaviais, juncos e, em menor grau, de ciperáceas $^{21}$, albergando uma grande diversidade biológica, pelo que será importante minimizar os efeitos deste fenómeno na REM.

\section{Finalidade, Missão e Importância da Reserva Especial do Maputo}

A finalidade da Reserva Especial de Maputo tem mudado ao longo do tempo. A REM foi estabelecida originalmente para proteger a população de elefantes, que existia na área². No entanto, a sua finalidade foi expandida em 1969, para incluir a proteção de outras espécies de grandes mamíferos (e.g., hipopótamos, cudos, girafas). Em 1990 foi alargada a sua finalidade com o reconhecimento crescente para a importância da biodiversidade. Atualmente, a sua finalidade é contribuir para o sistema de áreas protegidas de Moçambique ao conservar a biodiversidade que ocorre nesta zona costeira que fica na região biogeográfica de Tongaland-Pondoland e combina os ecossistemas costeiros e terrestres ${ }^{2}$.

Neste contexto, estabeleceu-se como missão da REM, a conservação da biodiversidade dos ecossistemas marinhos, da conectividade ecológica e da promoção de benefícios equitativos para as comunidades afetadas. Assim, as comunidades que vivem dentro e nas áreas adjacentes à REM deverão participar e ser corresponsáveis pela gestão sustentável da $\mathrm{REM}^{2}$. A região contém elevados níveis de riqueza de espécies e também inclui o Parque de zona húmida de iSimangaliso (maior complexo estuarino de África com oito ecossistemas interdependentes, todos com elevada diversidade de fauna e flora) que foi declarado em 1999 pela UNESCO Património Mundial. Por outro lado, as comunidades locais ao dependerem da captura de recursos naturais para o seu sustento também podem ajudar a manter a biodiversidade ${ }^{2}$. Uma vez que se reconhece a importância das comunidades na manutenção da biodiversidade da REM pelas práticas tradicionais usadas, estas deveriam ser consultadas e ter uma ação ativa na gestão da conservação. Assim, e para a Direção Nacional de Áreas de Conservação², a REM apresenta vários atributos importantes a conservar, dos quais se destacam:

a) Centro de Diversidade de Plantas de Maputaland - Parte da REM está situada no centro de endemismo de plantas na África do Sul. Esta Reserva fica numa posição estratégica no limite Sul dos trópicos, onde se encontram inúmeras espécies de zonas temperadas de Sul e onde se observa a distribuição no limite Sul de muitas espécies. 0 estado dos endemismos encontrados na REM não é bem conhecido, mas através da comparação com áreas adjacentes, prevê-se que os endemismos serão em maior número do que os registados atualmente; 
b) Diversidade da comunidade de plantas - A REM apresenta uma enorme variedade e combinação de comunidades de plantas terrestres e ecossistemas, alguns dos quais sem qualquer estatuto de proteção na África do Sul. Estes ecossistemas incluem planícies aluviais, savanas, mangais, florestas pantanosas, florestas secas de Licuati e matas de areia, floresta de dunas costeiras, pastos secos e pastos higrófilos (água doce e salgada), com espécies de flora únicas. Associada a esta variedade de ecossistemas, está provavelmente uma riqueza de espécies que ainda não foi totalmente inventariada;

c) Comunidades de pântanos de importância internacional - Existe na REM e nas áreas adjacentes uma variedade e extenso sistema de pântanos, que incluem comunidades fluviais e de estuários, leitos de plantas marinhas, mangais, pastos higrófilos de água doce e salgada, leitos de juncos e ciperáceas, floresta pantanosa, sistemas de lagos costeiros de água doce e salgada e linha costeira marinha com recifes de arenitos a suportar as comunidades de corais muito diversas desta sub-região;

d) Peixes e populações de répteis - A REM apresenta pelo menos três espécies de peixes endémicos, de acordo com o Centro de Endemismo de Plantas de Maputaland. Mais ainda, a linha costeira marinha é um local de berçário importante para a tartaruga-gigante e para a tartaruga-boba. A REM contém ainda uma população saudável de crocodilos do Nilo. 0 endemismo de espécies destes grupos é elevado, especialmente em espécies fossadoras (que escavam tocas, e.g., Caranguejos fantasma - Ocypode spp.) nas florestas de dunas;

e) Aves e Pássaros - A REM suporta uma grande variedade de espécies de aves devido à sua ampla gama de habitats, incluindo vários pássaros listados na CITES (Convention on International Trade in Endangered Species of Wild Fauna and Flora), três espécies e 47 subespécies que são consideradas endémicas para o Centro de Maputaland;

f) Populações de mamíferos de grande porte - A REM contém uma população reprodutora de mais de 350 elefantes Loxodonta africana (Blumenbach, 1797), concentrados essencialmente na parte Noroeste. Esta é a última grande população de elefantes na Província de Maputo e a que se encontra mais a sul de Moçambique. Prevê-se que, em conjunto com a população do Parque de Elefantes de Tembe, estes elefantes constituam uma população geneticamente distinta;

g) Locais sagrados e culturais - Existe uma série de locais de culto como funerais sagrados e cerimoniais de grande importância para os residentes na área da REM.

Regra geral, os recursos naturais na Reserva Especial de Maputo formam uma componente muito importante na subsistência das comunidades residentes e adjacentes. Isto inclui a pesca, o mel, materiais de construção (estacas, erva e junco), plantas alimentares selvagens, plantas medicinais e animais de caça. Embora reconhecendo o contributo das comunidades locais na manutenção da biodiversidade, tem sido dada pouca ênfase à exploração do substrato epistemológico subjacente ao papel das comunidades na conservação da biodiversidade da REM ao longo do tempo. Neste sentido o interesse no estudo desta reserva e das suas comunidades prende-se com a necessidade de explorar o conhecimento das comunidades locais no contributo para um modelo de conservação e gestão da biodiversidade mais sustentável. 


\section{REFERÊNCIAS}

${ }^{1}$ MARULO, A., Turismo e meio ambiente: uma análise do ecoturismo e sua contribuição sócio-ambiental no Distrito Matutuine: caso da Reserva Especial de Maputo, Moçambique. Dissertação de Mestrado em Turismo e Desenvolvimento Regional e Gestão em Turismo - Universidade Federal do Rio Grande do Norte, 13-123. 2012.

2 DNAC, Plano de Gestão da Reserva Especial de Maputo, 1-108. 2009.

${ }^{3}$ INE, Estatísticas do Distrito de Matutuíne, 5-18. 2010

${ }^{4}$ PEREIRA, M., Recursos Turísticos e Pesqueiros da Zona Costeira do Distrito de Matutuíne, Maputo. Relatório submetido ao WWF Mozambique Coordination Office no âmbito do projecto - Challenges for Conservation on the Developments of the Maputo and Libombos Corridors, 1-25. 2004.

${ }^{5}$ SOTO B., Perceptions of the Forestry and Wildlife Policy by the local communities living in the Maputo Elephant Reserve, Mozambique. Biodiversity and Conservation, 1723-1738. 2001.

${ }^{6}$ ANAC, Relatório da Reunião Nacional das Áreas de Conservação, 1-26. 2017

${ }^{7}$ MINISTÉRIO DO ULTRAMAR, Boletim Oficial de Moçambique, 825-828. 1960

${ }^{8}$ NTELA, P., Categorias de conservação e gestão de áreas protegidas em Moçambique: "Reserva Especial de Maputo, uma categoria complexa e confusa". Revista VITAS - Visões Transdisciplinares sobre Ambiente e Sociedade, Ano III, 6, 1-40. 2013.

9 Estratégia e Plano de Acção para a Conservação da Diversidade Biológica de Moçambique, Ministério da Terra, Ambiente e Desenvolvimento Rural, Maputo, 1-133. 2008.

${ }^{10}$ LOURO, C.M., Perfis ecológicos de espécies e ecossistemas costeiros de Moçambique: dunas costeiras. Relatório de Investigação, 1-28, 2005.

${ }^{11}$ CONCEIÇÃO, A.W. et al., Impacto das políticas de conservação da natureza na dinâmica das comunidades locais no Parque Nacional do Limpopo (Moçambique). Revista Argumentos Montes Claros, 275-295. 2017.

${ }^{12}$ ARRUDA, R., "Populações tradicionais" e a proteção dos recursos naturais em unidades de conservação. Ambiente \& sociedade, 79-92. 1999.

${ }^{13}$ VODOUHÊ F.G. et al., Community perception of biodiversity conservation within protected areas in Benin. Forest Policy and Economics, 505-512. 2010

${ }^{14}$ LOURO, C., et al., Relatório Anual de Governação Ambiental: Desafios e Oportunidades de Gestão das Áreas de Conservação Marinhas em Moçambique, 5-116. 2016

${ }^{15}$ ORMSBY, A. et al., A framework for understanding community resident perceptions of Masoala National Park, Madagascar. Environmental Conservation, 156-164. 2005.

${ }^{16} \mathrm{ADOM}, \mathrm{D} .$, Inclusion of local people and their cultural practices in biodiversity conservation: lessons from successful nations. American Journal of Environmental Protection, 67-78. 2016

${ }^{17}$ HUNT, I.J. et al., Biocultural design: a new conceptual framework for sustainable development in rural indigenous and local communities. In: SAPI EN. S. Surveys and Perspectives Integrating Environment and Society, 33-43. 2012.

${ }^{18}$ IZQUIERDO, E. et al., Barriers and triggers to community participation across different stages of conservation management. Environmental Conservation, 239-249, 2010

${ }^{19}$ INFIELD, M. et al., Community attitudes and behaviour towards conservation: an assessment of a community conservation programme around Lake Mburo National Park, Uganda. Oryx, 48-60. 2001.

${ }^{20} \mathrm{CHARNLEY}$, S. et al., Integrating traditional and local ecological knowledge into forest biodiversity conservation in the Pacific Northwest. Forest ecology and management, 14-28. 2007.

${ }^{21}$ DNAC, Proposta para a Demarcação e Gestão do Corredor de Futi. Documento do projeto TFCA (Transfrontier Conservation Areas), como proposta para a demarcação e gestão do Corredor de Futi, 3-40 2002. 